\title{
Daily Life and Challenges Faced By Households With Permanent Childhood Developmental Disability in Rural Tanzania - A Qualitative Study
}

\author{
Joëlle Castellani ${ }^{1}$ - Omari Kimbute ${ }^{2}$. Charles Makasi ${ }^{2} \cdot$ Zakayo E. Mrango $^{2}$. \\ Aggie T. G. Paulus ${ }^{1}$ - Silvia M. A. A. Evers ${ }^{1} \cdot$ Pip Hardy $^{3} \cdot$ Tony Sumner $^{3}$. \\ Augusta Keiya $^{4}$ - Borislava Mihaylova ${ }^{5,6}$ - Mohammad Abul Faiz ${ }^{7}$. \\ Melba Gomes ${ }^{8}$
}

Accepted: 19 July 2021 / Published online: 2 October 2021

(c) The Author(s) 2021

\begin{abstract}
Severe developmental disability in children affects the life of the child and entire household. We conducted a qualitative study to understand how caregivers manage severe developmental disabilities in children in rural Africa. Families and six children (out of 15 children) who had serious permanent sequelae from a cerebral infection in Handeni, Tanzania, were contacted and invited to a workshop to recount their experience living with severe developmental disabilities. After consent, individual interviews were conducted first through recording of individual digital stories and then through individual semi-structured interviews. Pre-determined key categories were used to analyse the data. Our results showed that developmental disabilities required constant care and reduced the autonomy of the children. Schooling had not been attempted or was halted because of learning problems or inability to meet specialized school costs. Parents were under constant physical, emotional and financial stress. Their occupational earnings decreased. Some families sold their assets to survive. Others began to rely on relatives. Understanding the consequences of developmental disability helps to identify where social support should be focused and improved.
\end{abstract}

Keywords Developmental disability $\cdot$ Poverty $\cdot$ Africa $\cdot$ Challenges

Joëlle Castellani

j.castellani@alumni.maastrichtuniversity.nl

Extended author information available on the last page of the article 


\section{Background}

Severe developmental disability in children alters a child's life and that of the family but the consequences have rarely been detailed. In developing countries, the impact might be greater because of poverty, difficult living conditions and poor access to care and rehabilitation. Consequently, children with severe developmental disability may have lower school attendance (Eide \& Kamaleri, 2009; Filmer, 2008; Trani \& VanLeit, 2010), lower educational attainment (Filmer, 2008; Mont \& Cuong, 2011; Trani \& Loeb, 2012) and fewer adult employment opportunities (Mitra, 2008; Mitra \& Sambamoorthi, 2008; Trani \& Loeb, 2012). Families with disability are generally poorer (Filmer, 2008), have fewer possessions (Mitra et al., 2011; Palmer et al., 2012), live in worse conditions (Eide \& Kamaleri, 2009; Loeb \& Eide, 2004) and experience a higher level of stress than families without disability (Mobarak, 2000). Disability is reported to tip households into poverty and transfer poverty to the next generation (Yeo \& Moore, 2003).

Research on developmental disability has usually been quantitative, classifying the short and long-term clinical, neurological and cognitive impairments (Bangirana et al., 2016; Birbeck, 2013; Idro et al., 2016; Khandaker et al., 2014; Michaeli et al., 2014). The economic consequences for different types of disabilities have also been quantified for patients, households (Eide \& Kamaleri, 2009; Filmer, 2008; Lamichhane \& Kawakatsu, 2015; Trani \& Loeb, 2012) and caregivers (Cheshire et al., 2010; Dambi et al., 2015; Sawyer et al., 2011). Challenges faced by caregivers and coping strategies to overcome these barriers have been described but there are quite limited data on the burden of caring for children with developmental disabilities in rural Africa, and how this burden changes as the child develops (Gona et al., 2011; Hartley et al., 2005; McNally \& Mannan, 2013). We carrried out a qualitative study of adolescent children with serious permanent developmental sequelae ranging from major cognitive impairments to severe physical restrictions, or both to document the perceptions of caregivers on (1) their child's development, (2) the treatment, (3) their emotional and physical burden, (4) their challenges and (5) their coping strategies over a 10-year period after the initial sequelae.

\section{Methods}

\section{Study Participants}

In 2014, the families of six children (out of 15 children) with persistent sequelae after a cerebral infection that had occurred at least 10 years earlier were asked for consent to meet, recount their stories and be interviewed about their lives in a 2-day workshop. All six parents/guardians consented and were reimbursed for accommodation, meals and transport costs.

The six children (four females and two males) were aged between 9 and 13 years (Table 1). Four children were accompanied by their mother, one by her 


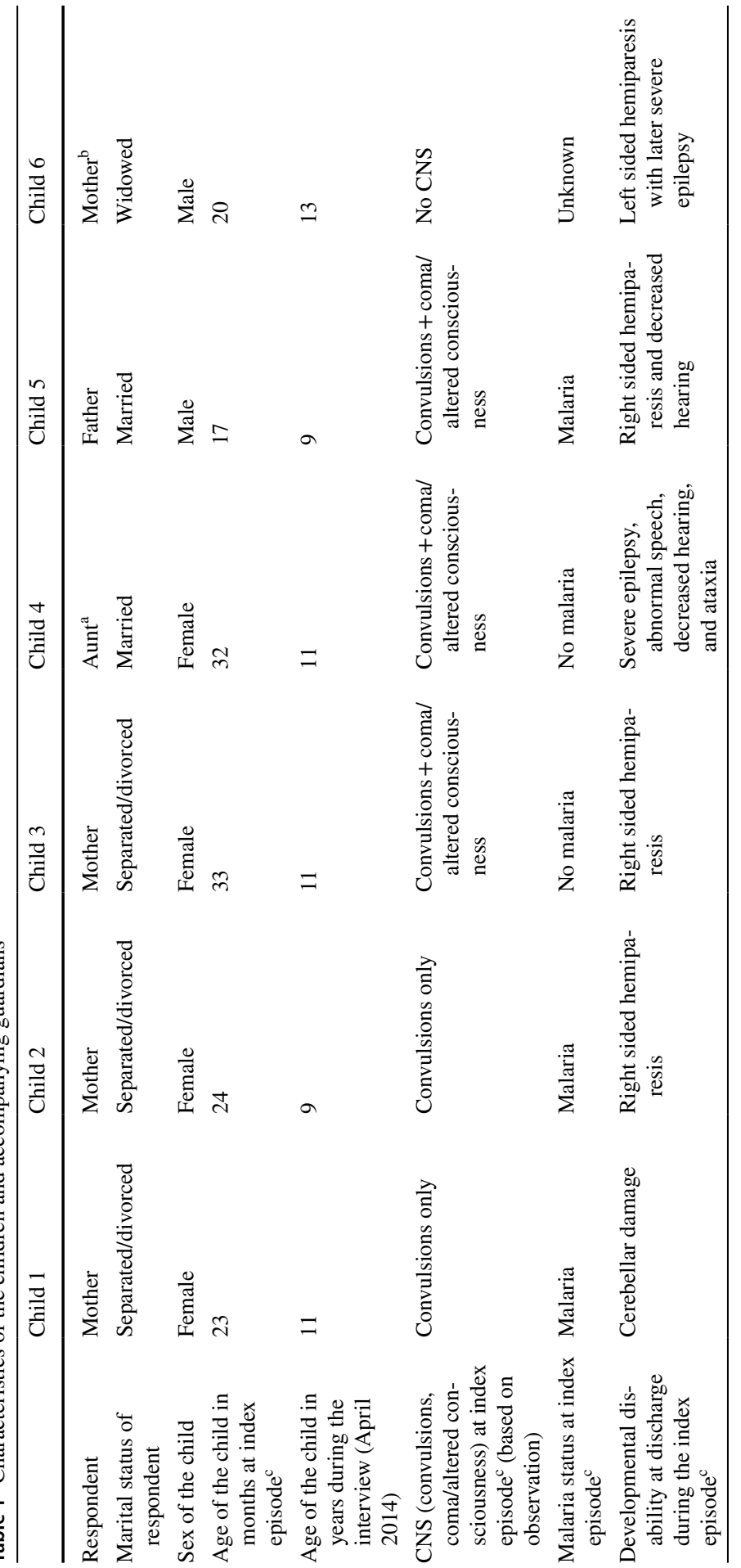




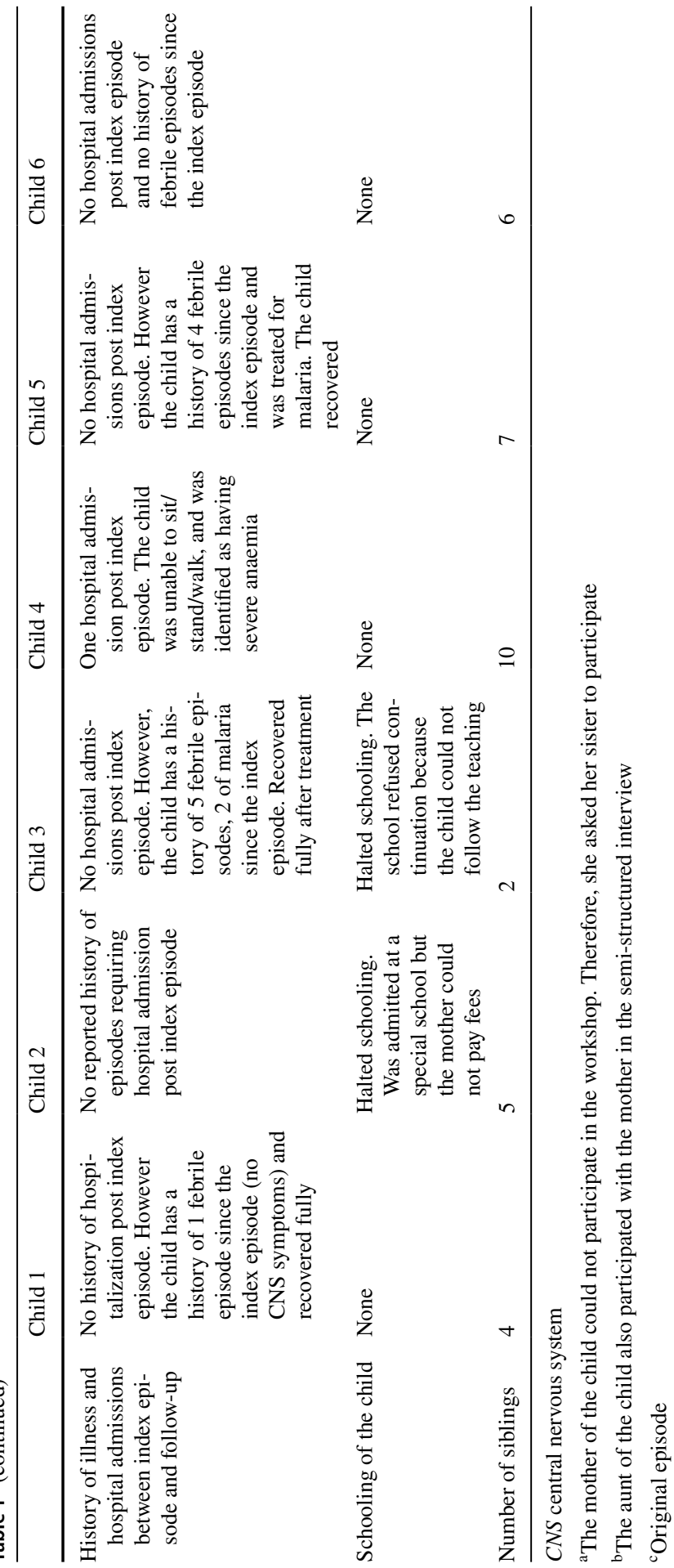


aunt and one by his father. Two parents were married, three were separated or divorced and one was widowed. Five children had either convulsions or coma or both in the episode that caused developmental disabilities. Except for one child who had been hospitalized (child 4), none of the other children reported any hospital admissions since the initial episode, although they experienced uncomplicated malaria episodes that did not require hospital admission (child 1: 1 episode; child 3: 5 episodes; child 5: 4 episodes).

\section{Current Developmental Disabilities}

All six children had one or more profound physical and/or cognitive disabilities (Table 2). Child 1 had limited cognition, was unable to speak, could not follow instructions and was reported to play only with much younger children. Child 2 could only walk on her knees and had elbow constrictions in her left arm. Child 3 had motor problems, abrupt changes of behaviour and partial hearing loss. Child 4 had epilepsy, dysconjugate gaze, impaired gait, made unsteady movements and frequently fell, could not articulate words, was doubly incontinent and was described as having limited cognition. Child 5 had problems with the right upper and lower limbs. Child 6 could not straighten his legs and therefore could not stand, had limited vision and hearing and was unable to speak; he was diagnosed with epilepsy and was described as having restricted cognition.

\section{Data Collection}

The data were first collected through individual stories of the families, which were digitally recorded (Patient Voices, n.d.) and then through an individual semistructured interview. All data were collected during the 2-day workshop.

Digital individual stories Each parent/guardian was free to choose specific moments of life regarding the illness/developmental disability of their child. They outlined what they wanted to say in their own words and were permitted to focus on their feelings, the impact of the illness/developmental disability and the challenges they faced associated with caring for a child with developmental disabilities (Patient Voices, 2014). The individual digital stories were recorded in Swahili by the parents/guardians and then translated and recorded in English by a local researcher fluent in both languages.

Semi-structured interviews Once the digital stories were recorded, an individual semi-structured interview with parent-child pairs on the challenges of living with and caring for a child with developmental disabilities was completed. For this purpose, a questionnaire was used, containing open questions on seven topics on how developmental disability affects daily life: worries of the parents/guardians; the physical efforts of the carer; the effects of developmental disability on carer's time; the child's needs and medications used; social relationships; discipline/mood; and 


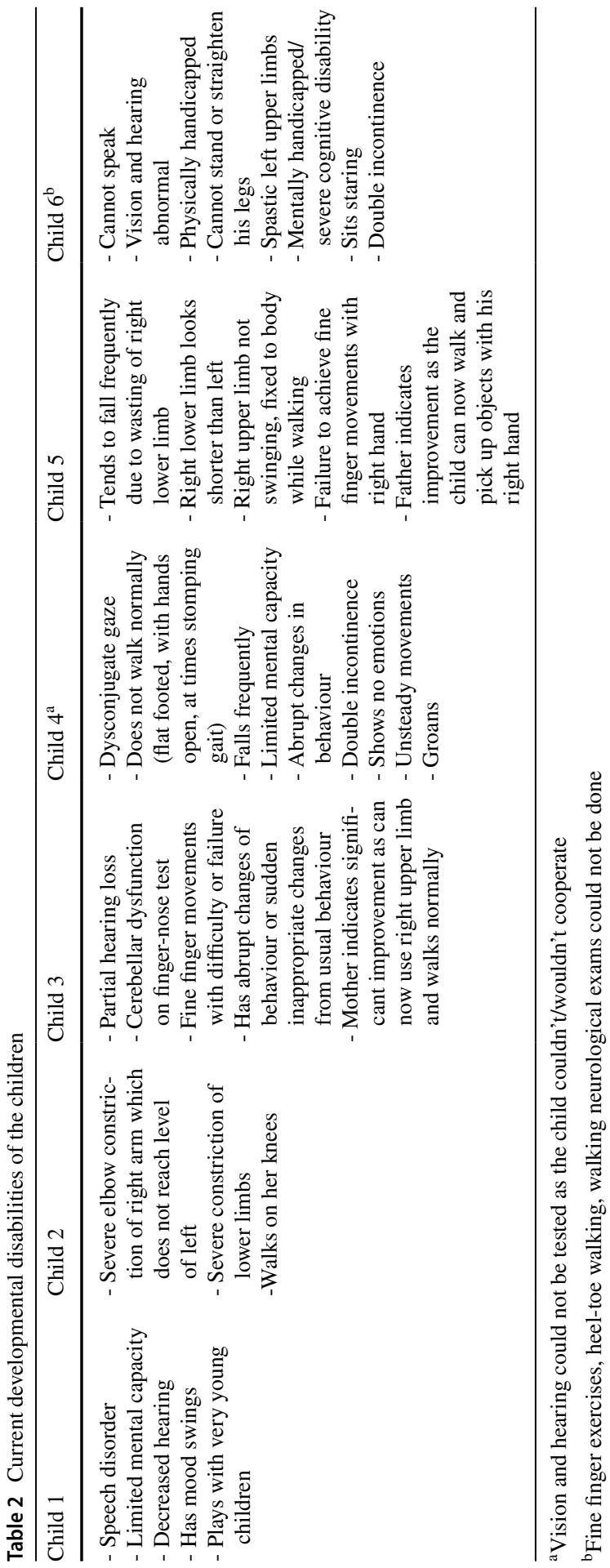


Table 3 Examples of questions of the case report form

\begin{tabular}{|c|c|}
\hline Categories & Questions \\
\hline Worries of the parents/guardians & $\begin{array}{l}\text { Could you please tell me more about how the developmental dis- } \\
\text { ability of your child affects you? } \\
\text { Examples of elements to be included: } \\
\text { - More stress, sadness and worries? } \\
\text { - How do you see the future for you, your child and your family? }\end{array}$ \\
\hline Physical efforts of the carer & $\begin{array}{l}\text { Could you please tell me how you are physically affected? (For } \\
\text { instance, how do you deal if your child cannot walk?) } \\
\text { Examples of elements to be included: } \\
\text { - More physical efforts? } \\
\text { - If yes, do you have any health problems due to these additional } \\
\text { physical efforts? } \\
\text { - Are you feeling exhausted by these additional efforts? }\end{array}$ \\
\hline $\begin{array}{l}\text { Effects of developmental disability } \\
\text { on carer's time }\end{array}$ & $\begin{array}{l}\text { Could you please tell me more about how your time is affected by } \\
\text { the developmental disability of your child when comparing to a } \\
\text { child who has no developmental disability? } \\
\text { Examples of elements to be included: } \\
\text { - When you are at home, are you always together with him/her the } \\
\text { whole day? } \\
\text { - How do you manage your time at home? Is some of your time } \\
\text { allocated to basic stuff such as dressing, feeding, toileting, sleep- } \\
\text { ing etc.? In which areas? } \\
\text { - Do you have some extra help? If yes, what kind of "other" help } \\
\text { do you have? }\end{array}$ \\
\hline
\end{tabular}

Child's needs and medications used Could you please tell me how you deal with your child's needs, medication and special treatment?

Examples of elements to be included:

- How do you understand your child's needs (because cannot speak)?

- Need of special treatment?

- What about the toilet? What help does your child need?

- Need to take drugs regularly?

Social relationships

Could you please let me know how your relations with your family and other people have been affected and how your child is socially affected?

Examples of elements to be included:

- How has your child been with his/her siblings over the past month? Do they argue much?

- Are there other children around here who your child can play with? If yes, is (s)he willing to play with them? Are they playing together?

- Have you or your child already been socially excluded?

- Have you already encountered some difficult situations within the family (e.g. father left)?

Discipline/mood

Could you please tell me how you deal with discipline? Do you think your child is more difficult than a child with no developmental disability? Is (s)he often angry, does (s)he scream a lot?

Examples of elements to be included:

- Mood changes frequently?

- Has explosive, angry outbursts?

- What does your child do when angry?

- Does (s)/he scream and kick? How many times in the past month? 
Table 3 (continued)

\begin{tabular}{ll}
\hline Categories & Questions \\
\hline Financial issues & What are the financial consequences for your household? \\
& Examples of elements to be included: \\
& - Did you need to give up or change your job? Or did you need to \\
& work less? \\
- If you have any other children, how are they affected? Do they \\
also need to allocate their time to take care of the child? Maybe \\
they cannot go to school or do their homework? Did some of your \\
children need to give up school in order to work? \\
$\bullet$ Have you already encountered a lack of food?
\end{tabular}

financial issues (Table 3). The interview questions and the seven topics were based on previous literature (Davis et al., 2010; Gona et al., 2011; Hartley et al., 2005; Murphy et al., 2007) and on the Behaviour Questionnaire for Parents - a questionnaire developed in East Africa adapted from the Kaufmann Assessment Battery for Children (Kaufman \& Kaufman, 2004) which assesses behaviour difficulties in the home. Open questions (developed in English, translated into Swahili) on the seven topics, asked in the same sequence, guided the interview. The six interviews were conducted in Swahili by only one experienced bilingual researcher and each interview lasted about 30 minutes. Answers were immediately translated into English and transcribed, with clarifications on meaning sought, as necessary, during the workshop.

\section{Data Analysis}

We analysed the data from both the digital stories and the semi-structured interview by using key categories that were pre-determined according to the seven topics of the semi-structured interview and previous research (Davis et al., 2010; Gona et al., 2011; Hartley et al., 2005; Murphy et al., 2007). Each digital story and interview transcription was read several times. Meaning units were extracted by the first author and copied into a spreadsheet where they were condensed and assigned a code. Each code was then placed under a pre-determined key category into a hierarchical frame.

\section{Results}

The results are presented into five main themes, namely: (1) the child's development, (2) the treatment, (3) the emotional and physical burden of the parents/guardians, (4) the challenges and (5) the coping strategies (Table 4). Each main themes were then separated into sub-topics.

\section{Child's Development}

Three main sub-topics emerged from the data: (1) autonomy, (2) communication and understanding and (3) behaviour and socialization. 


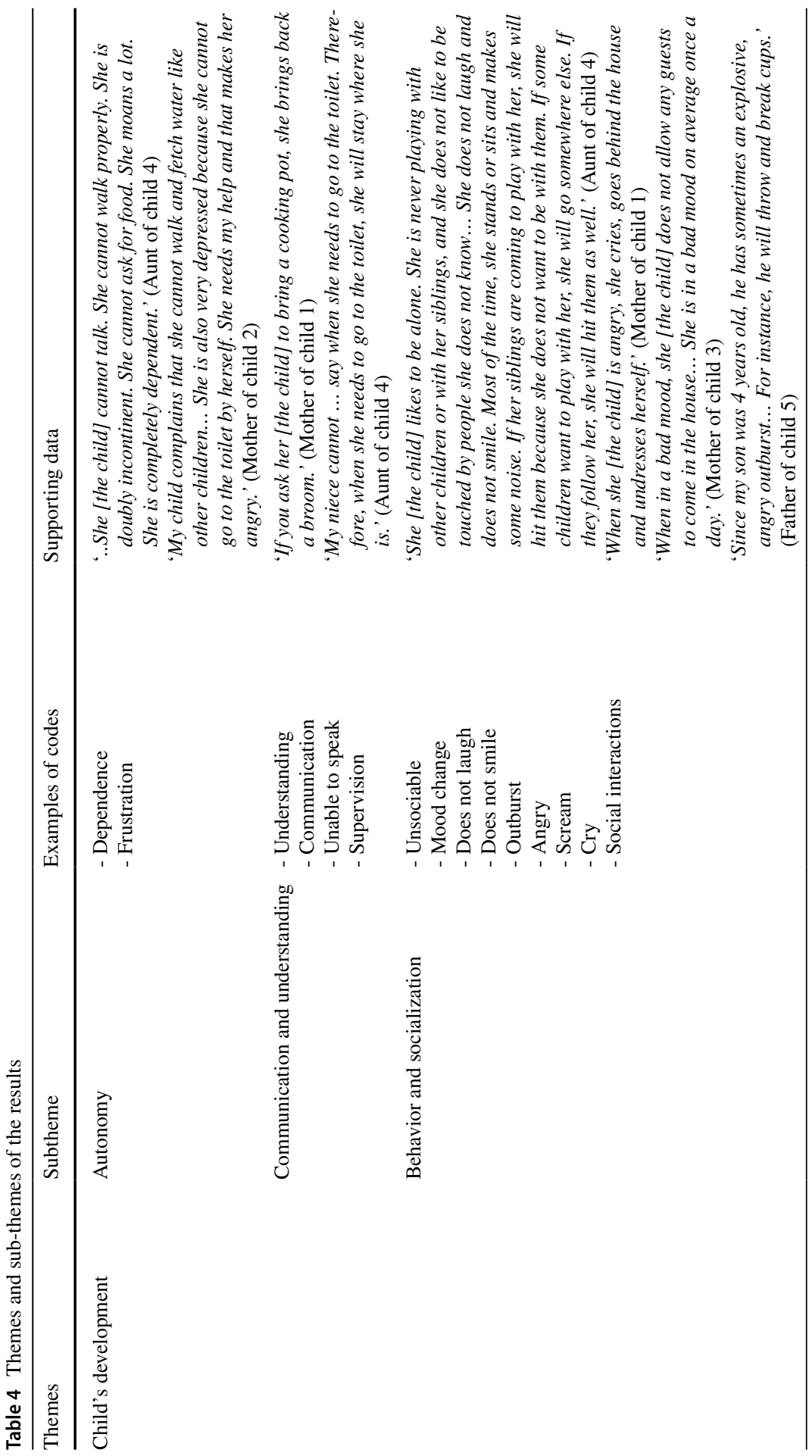




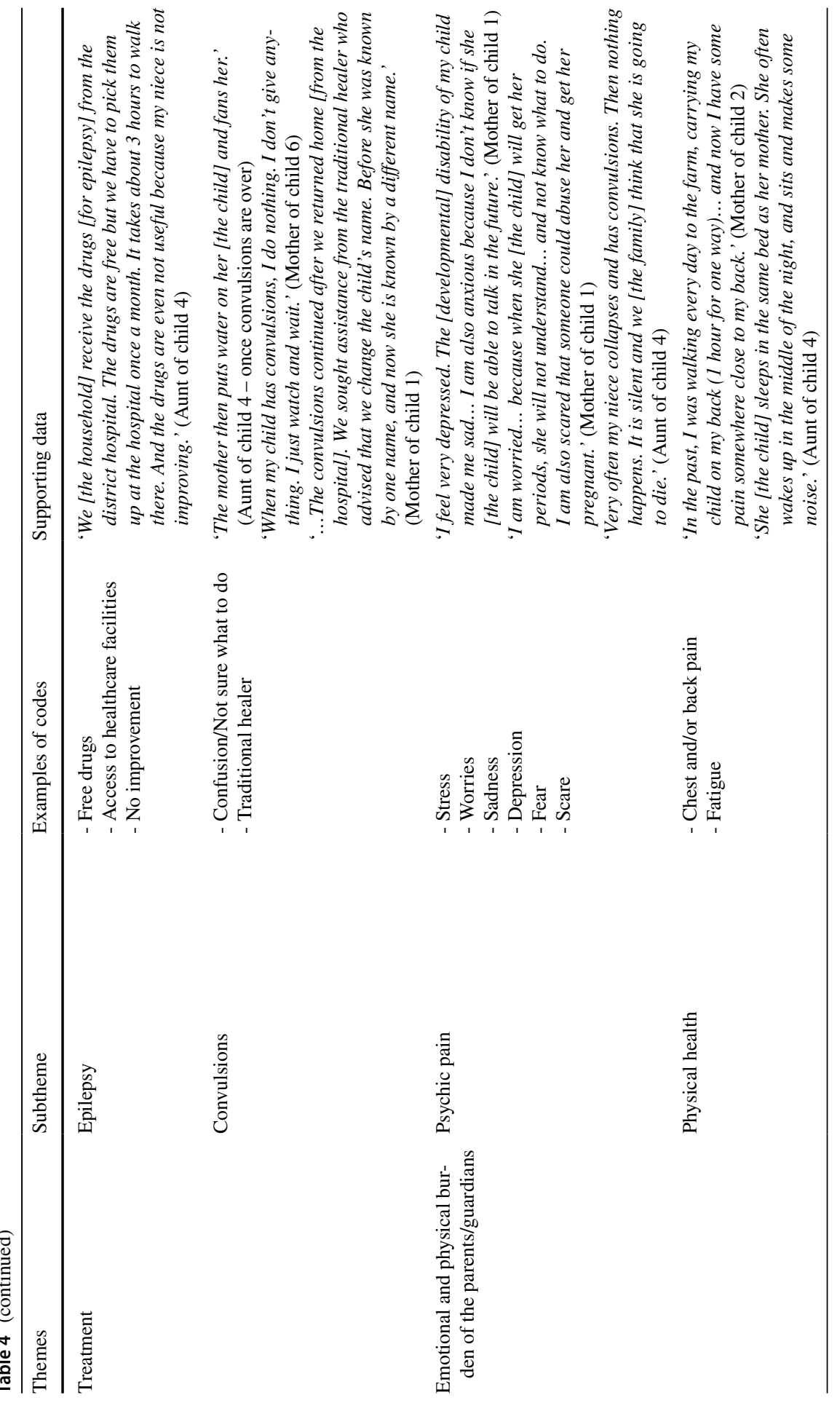




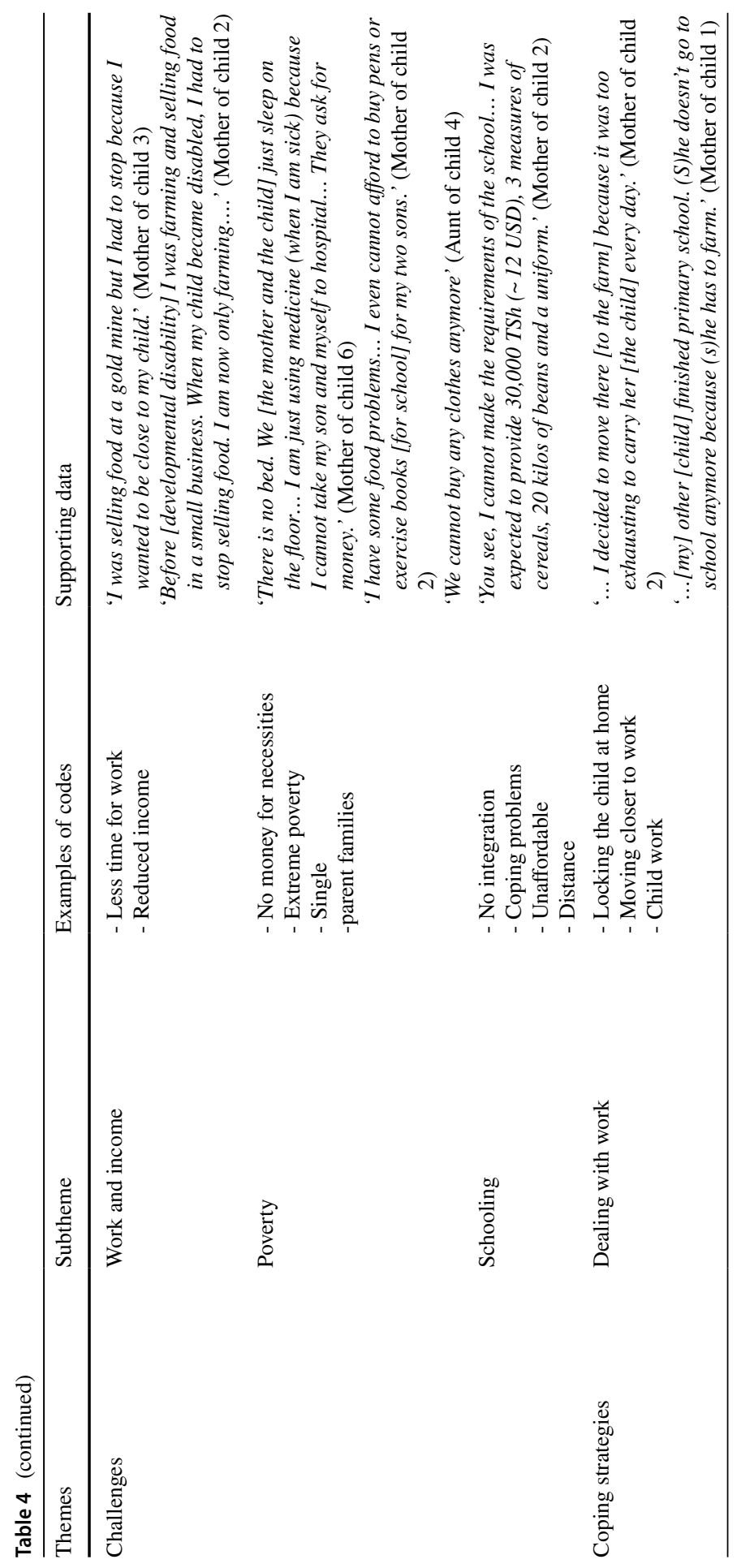




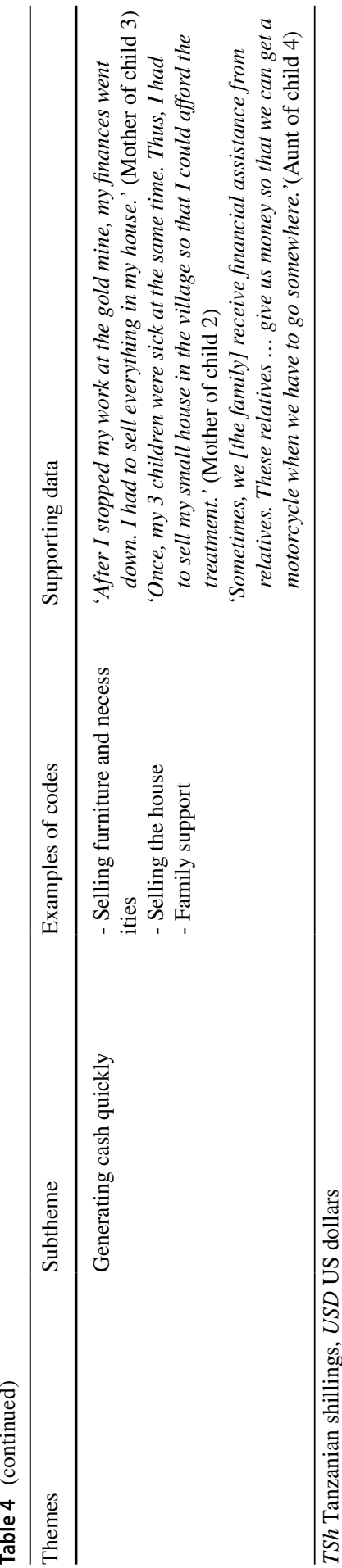


Autonomy The data showed that developmental disability affected the child's autonomy. Most children with developmental disabilities were dependent on their parents/guardians who fed, dressed and bathed them.

For children with only physical disabilities who are aware of their disabilities, a lack of autonomy led to sadness, frustration, depression and anger especially when children were constantly dependent on somebody else for toileting and unable to do things that children of their age would normally do.

Communication and understanding For children with limited mental capacity, understanding or retaining information was difficult. In some cases, communication was not possible when children were unable to speak and could not communicate that they were hungry, or needed to go to the toilet or that they were not feeling well. Constant supervision was often required because if left unattended, even for a few minutes, children might leave home and not know how to return.

Behaviour and socialization The guardians described how developmental disabilities affected the behaviour and socialization of their child. Serious social problems were mentioned in relation to children with mental disabilities and epilepsy. Children with epilepsy or mental disabilities were socially disengaged. They exhibited unsociable behaviour and did not respond in ways which were normally expected; their responses and changes in facial expressions suggested that they did not know which behaviours were appropriate and which were not. This apparently led to social interaction problems with both adults and children.

For children with epilepsy or with frequent convulsions and emotional outbursts, mood changes were sudden and could greatly impact on the quality of life of the children and their families. Unpredictable outbursts were often difficult to control. Even for parents of children who are not mentally disabled, the attitude of their child might be unpredictable, extreme and uncontrollable which made it difficult to manage.

\section{Treatment}

This topic was separated into two sub-topics: (1) epilepsy and (2) convulsions.

Epilepsy Only one child who had epilepsy received regular treatment (child 4). Drugs for epilepsy are usually free and available from healthcare facilities. However some healthcare facilities, especially those that can manage epileptic cases, are located far away from communities, and therefore, access to treatment is difficult. Parents must walk long distances and may not have funds for transport.

Convulsions The data showed that parents were not sure what to do when their child convulsed. Often parents did nothing or just put water on the child. However 
for one mother, traditional medicine was a solution. She was told by a traditional healer that the convulsions were caused because evil spirits were looking for her child, and therefore it was important to deal with them by changing the name of the child before healing could occur.

\section{Emotional and Physical Burden of the Parents/Guardians}

This topic was separated into two sub-topics: (1) psychic pain and (2) physical health.

Psychic pain All parents/guardians expressed fear, stress, depression, sadness and/ or worry because of the developmental disability of their child. The normal stresses and worries of bringing up a child with developmental disability became even more important when the father had left the household and/or when the parents did not know if the condition of their child would improve.

With age and the hormonal and physical changes of adolescence, more difficulties were anticipated. Bringing up a female child was associated with increased level of stress, fear and worries as parents were concerned that their child would never be able to protect herself from her lack of understanding on sexual matters.

Fear of not being available or not knowing what to do when convulsions occurred was often expressed by carers. Convulsions caused the family to panic or be extremely sad, and parents/guardians said they feared the worst when the epileptic seizures ceased and the child fell into a deep sleep of unconsciousness.

Physical health Parents/guardians described physical fatigue and back and/or chest pain caused by children who were unable to walk because this meant that they had to carry their child, usually on their back (children 2, 4 and 6). In addition, some mothers mentioned that they were often exhausted because they had to sleep in the same bed as their child which created discomfort.

\section{Challenges}

This section had three main topics: (1) work and income, (2) poverty and (3) schooling.

Work and income The child's developmental disability influenced household's life and limited income-generating activities of the family. The time required to take care of the child meant reduced time to work to earn an income and often the parents had to choose whether they should take care of their child or whether they should continue to work. The difficulties increased when the mother became the only sole economic provider because the father left the household.

Poverty The data showed that because of a reduction in work, income decreased and households had a lower quality of life. The parents mentioned that they did not 
have the necessary funds to buy basic necessities such as food, medicine, school materials, furniture or clothes. In some cases, developmental disability pushed households into extreme poverty.

Schooling Only two children (children 2 and 3) had ever gone to school; neither could continue (Table 1). Child 3, who had partial hearing loss, motor problems and mental disability, went to two different mainstream (normal) schools but as she was not able to cope, the schools did not wish her to continue. Because it is difficult for a child with developmental disabilities to go to a normal school, parents stated that they would like to enrol their child in a specialized school. However, education in such schools is fee based and unaffordable for families living in rural areas, especially when the mothers are divorced and the sole provider of the household. This was the case for child 2. She had started in a (specialized) boarding school, which did not require fees for the first year but was not allowed to stay beyond a year because her mother could not pay the tuition fees for the second year.

For the other four children - one with severe cognitive disability (child 1), two with epilepsy, limited cognition, physical disability and speech impairments (children 4 and 6) and one with severe lower limb weakness and restricted upper limb abilities (child 5) - school was never initiated (Table 1). For child 5, the walking distance to the school contributed to a decision not to enrol the child in school.

\section{Coping Strategies}

Coping strategies was separated into two sub-topics: (1) dealing with work and (2) generating cash quickly.

Dealing with work Most parents/guardians had to reduce their working time or had to stop working. In order to continue to work and generate an income, a solution mentioned by a widow mother (child 6) was to lock her epileptic child at home (who was moody and jumped around the house) while she was working at the farm. However, this strategy worked for some time when the child had fewer fits and was younger, but when the child started to convulse more often, he became a danger to himself when left alone. Another mother (child 2) who had to walk every day to her farm (1 hour each way) by carrying her child who could not walk on her back found a radical solution to continue working by moving home to her farm even if this meant a decrease in her quality of life. For other families, trying to keep the same level of work (and income) as before was made possible through the help of siblings although this implied the siblings dropped out of school.

Generating cash quickly The data revealed that in order to survive, some parents/ guardians decided to sell their personal assets. For others, the extended family was an important source of finance. 


\section{Discussion}

Three major consequences of developmental disability emerged from the data: significant emotional and physical burden of caring for children with developmental disabilities, a decrease in work and unrelenting financial pressure on family income, assets and savings, and no or reduced school attendance for the child.

Caring for a child with developmental disabilities placed an emotional and physical burden on families. Children were dependent, needed assistance with daily tasks and activities and had little prospect of later improvement. Children with epilepsy had unpredictable seizures. Parents felt the constant pressure of being physically present for their dependent child. Consequently, as confirmed by other studies, all parents were exhausted, stressed, depressed and worried (Cheshire et al., 2010; Dambi et al., 2015; Davis et al., 2010; Sawyer et al., 2011). Some expressed desperation. Difficulties in communicating and understanding the needs of children with mental disability increased parental stress, anxiety, and depression both about the current circumstances (Hartley et al., 2005) as well as about the future. As mentioned elsewhere, physical disability increased the physical burden of carers looking after a child (Brehaut et al., 2004; Dambi et al., 2015; Davis et al., 2010; Hartley et al., 2005). Stress and distress were voiced by mothers whose spouse had abandoned the household, leaving them to support the whole family. Long-term developmental disability appeared to damage carers' health, destroy family structures, and reduce the quality of family life (Mobarak et al., 2000).

Developmental disability has financial costs. Parents either left their occupations or worked less because their child required full-time care. As a result of a reduction in occupational work, household income decreased leading to financial problems in purchasing necessities such as food or clothes (Gona et al., 2011; Hartley et al., 2005; McNally \& Mannan, 2013). To cope with extra expenses, the families reported selling their assets thus pushing households who were already poor into extreme poverty (Mitra \& Sambamoorthi, 2008; Yeo \& Moore, 2003). Exiting from this poverty trap remains difficult as families may never have the necessary resources to do so.

Most children in our study never went to school. Children with epilepsy had difficulties in attending normal schools especially when the epileptic seizures were frequent, unexpected, or were followed by coma, drowsiness, confusion, irritability, aggression, dizziness, loss of concentration, memory problems and mood swings. Seizures caused memory loss and confusion, and children appeared to have significant problems with learning, language or behaviour throughout their childhood, in addition to social stigma (bullying, anxiety, depression, self-consciousness). For both children with physical and/or cognitive disability, the distance to the school, and the lack of infrastructure, adequate learning materials and trained teachers, made access to normal schools even more difficult (ACPF, 2014). In Uganda, the negative attitude of normal schools contributed to lack of enrolment (Hartley et al., 2005). Specialized schools are usually fee-based and often inaccessible both physically and financially. Similar results were found in other studies in Tanzania and Uganda (Hartley et al., 2005; McNally \& Mannan, 2013). Lack of education led to parental 
concerns about the future of their child (Hartley et al., 2005). Lower school participation led to lower educational attainment which translated into lower employment opportunities and lower income in adulthood (Filmer, 2008; Yeo \& Moore, 2003).

To improve the quality of life of both children and households and reduce stress, the risk of depression, worries, and isolation, social support has been shown to be effective (Ainbinder et al., 1998; Bray et al., 2017; Kerr \& McIntosh, 2000). However, the households only received family support. Social support can be found at specialized centres, such as community-based rehabilitation centres (Cameron et al., 2005; CCBRT, n.d.), even in Tanzania. Free home-based therapies for children with physical and/or mental disabilities as well as regular home and school follow-up visits are offered (Cameron et al., 2005; CCBRT, n.d.). Children are taught how to increase their independence (e.g. washing, moving from their bed to a chair) and how to help the household (e.g. washing the dishes) (Cameron et al., 2005). However, community-based centres are rare and most centres are located in major (urban) cities which are not accessible or expensive for households living in rural areas. Another option to support children with developmental disabilities and their families is the involvement of community rehabilitation facilitators to provide home visits, exercises and training in activities of daily living (ADL-i.e. eating; bathing; getting dressed; toileting; transferring and continence) (Chappell \& Johannsmeier, 2009). This kind of intervention can provide ADL independence and increase social integration, self-esteem, self-confidence, mobility and acceptance of developmental disability (Chappell \& Johannsmeier, 2009).

Our study is rare in examining how caregivers manage severe childhood developmental disabilities that occurred early in infancy and continued into adolescence without resolution. The ability to probe deeply through qualitative research on how developmental disability affects the family is a strength. Thematic saturation was achieved with the small number of children. However, the small number of children and parents interviewed does not provide a complete picture of the challenges in living with developmental disability. More topics might have emerged with a larger sample of parent-child pairs. A further limitation is that only one male guardian participated in the study and male views on the consequences of developmental disability, especially on stress, work and financial burdens, may differ from the views of female guardians. The qualitative interviews were not tape-recorded because ethical clearance was received only for recording digital stories (Patient Voices, 2014). Finally, only children with severely developmental disabilities took part in our research, and therefore, this study does not represent the challenges of caring for children with milder developmental disabilities.

\section{Conclusions}

Severe developmental disability affects not only the life of the child but that of the whole household. It increases physical, emotional and financial burdens of the child and carers. Children have very limited educational support-either from normal or specialized schools - and access to rehabilitative home-based support is inaccessible 
or unaffordable. Parental income is reduced because time for caring is increased and consequently households that are poor get pushed further into poverty.

Acknowledgements We would like to thank all children and their parents who agreed to be interviewed.

Funding This work was supported by the Grand Challenges Canada - Saving Brains Programme through the Mahidol Oxford Tropical Medicine Research Unit (MORU). This research was part of a larger project: "Long-term neurocognitive assessment of children following an episode of severe malaria: the artesunate suppository trial cohort". The study funders played no role in designing the study, collecting, analyzing and interpreting the data, and writing the final report. BM acknowledges support by NIHR Oxford Biomedical Research Centre.

Data Availability The digital stories are available under the following link: https://www.patientvoices.org. uk/savingbrains.htm.

\section{Declarations}

Ethics Approval Ethics approval for the full study, of which this was part, was obtained from the Oxford Tropical Research Ethics Committee, and the National Institute of Medical Research in Tanzania and with the 1964 Helsinki declaration and its later amendments or comparable ethical standards. Ethical clearance was received for recording digital stories.

Informed Consent Written consent was obtained from each guardian.

Conflict of Interest The authors declare that they have no conflict of interest.

Open Access This article is licensed under a Creative Commons Attribution 4.0 International License, which permits use, sharing, adaptation, distribution and reproduction in any medium or format, as long as you give appropriate credit to the original author(s) and the source, provide a link to the Creative Commons licence, and indicate if changes were made. The images or other third party material in this article are included in the article's Creative Commons licence, unless indicated otherwise in a credit line to the material. If material is not included in the article's Creative Commons licence and your intended use is not permitted by statutory regulation or exceeds the permitted use, you will need to obtain permission directly from the copyright holder. To view a copy of this licence, visit http://creativecommons.org/licen ses/by/4.0/.

\section{References}

Ainbinder, J. G., Blanchard, L. W., Singer, G. H., Sullivan, M. E., Powers, L. K., Marquis, J. G., et al. (1998). A Qualitative Study of Parent to Parent Support for Parents of Children with Special Needs. Consortium to Evaluate Parent to Parent. Journal of Pediatric Psychology, 23(2), 99-109.

Bangirana, P., Opoka, R. O., Boivin, M. J., Idro, R., Hodges, J. S., \& John, C. C. (2016). Neurocognitive Domains Affected by Cerebral Malaria and Severe Malarial Anemia in Children. Learning and Individual Differences, 46, 38-44.

Birbeck, G. L. (2013). Epilepsy in Africa: Caution and Optimism. The Lancet Neurology, 12(3), $220-222$.

Bray, L., Carter, B., Sanders, C., Blake, L., \& Keegan, K. (2017). Parent-To-Parent Peer Support for Parents of Children With a Disability: A Mixed Method Study. Patient Education Counseling, 100(8), 1537-1543.

Brehaut, J. C., Kohen, D. E., Raina, P., Walter, S. D., Russell, D. J., Swinton, M., et al. (2004). The Health of Primary Caregivers of Children With Cerebral Palsy: How Does it Compare With That of Other Canadian Caregivers? Pediatrics, 114(2), e182-e191.

Cameron, D. L., Nixon, S., Parnes, P., \& Pidsadny, M. (2005). Children With Disabilities in Low-Income Countries. Paediatrics \& Child Health, 10(5), 269-272. 
Chappell, P., \& Johannsmeier, C. (2009). The Impact of Community Based Rehabilitation as Implemented by Community Rehabilitation Facilitators on People With Disabilities, Their Families and Communities within South Africa. Disability and Rehabilitation, 31(1), 7-13.

Cheshire, A., Barlow, J. H., \& Powell, L. A. (2010). The Psychosocial Well-Being of Parents of Children With Cerebral Palsy: A Comparison Study. Disability and Rehabilitation, 32(20), 1673-1677.

Comprehensive Community Based Rehabilitation in Tanzania (CCBRT). (n.d.). Bringing Services Home. Accessed May 22, 2019. http://www.ccbrt.or.tz/programmes/disability/community-based-rehab/

Dambi, J. M., Jelsma, J., \& Mlambo, T. (2015). Caring for a Child with Cerebral Palsy: The Experience of Zimbabwean Mothers. African Journal of Disability, 4(1), 168.

Davis, E., Shelly, A., Waters, E., Boyd, R., Cook, K., Davern, M., et al. (2010). The Impact of Caring for a Child With Cerebral Palsy: Quality of Life for Mothers and Fathers. Child: care, health and development, 36(1), 63-73.

Eide, A. H., \& Kamaleri, Y. (2009). Living Conditions Among People With Disabilities in Mozambique: A National Representative Study. SINTEF.

Filmer, D. (2008). Disability, Poverty, and Schooling in Developing Countries: Results From 14 Household Surveys. The World Bank Economic Review, 22(1), 141-163.

Gona, J. K., Mung'ala-Odera, V., Newton, C. R., \& Hartley, S. (2011). Caring for Children With Disabilities in Kilifi, Kenya: What Is the Carer's Experience? Child: care, health and development, 37(2), 175-183.

Hartley, S., Ojwang, P., Baguwemu, A., Ddamulira, M., \& Chavuta, A. (2005). How Do Carers of Disabled Children Cope? The Ugandan Perspective. Child: care, health and development, 31(2), 167-180.

Idro, R., Kakooza-Mwesige, A., Asea, B., Ssebyala, K., Bangirana, P., Opoka, R. O., et al. (2016). Cerebral Malaria is Associated with Long-Term Mental Health Disorders: A Cross Sectional Survey of a Long-Term Cohort. Malaria Journal, 15, 184.

Kaufman, A. S., \& Kaufman, N. L. (2004). Kaufman Assessment Battery for Children (2nd ed.). American Guidance Service.

Kerr, S. M., \& McIntosh, J. B. (2000). Coping When a Child Has a Disability: Exploring the Impact of Parent-To-Parent Support. Child: care, health and development, 26(4), 309-322.

Khandaker, G., Muhit, M., Rashid, H., Khan, A., Islam, J., Jones, C., et al. (2014). Infectious Causes of Childhood Disability: Results From a Pilot Study in Rural Bangladesh. Journal of Tropical Pediatrics, 60(5), 363-369.

Lamichhane, K., \& Kawakatsu, Y. (2015). Disability and Determinants of Schooling: A Case From Bangladesh. International Journal of Educational Development, 40, 98-105.

Loeb, M., \& Eide, A. H. (2004). Living Conditions Among People With Activity Limitations in Malawi : A National Representative Study. SINTEF.

McNally, A., \& Mannan, H. (2013). Perceptions of Caring for Children With Disabilities: Experiences From Moshi, Tanzania. African Journal of Disability, 2(1), 21.

Michaeli, O., Kassis, I., Shachor-Meyouhas, Y., Shahar, E., \& Ravid, S. (2014). Long-Term Motor and Cognitive Outcome of Acute Encephalitis. Pediatrics, 133(3), e546-e552.

Mitra, S. (2008). The Recent Decline in the Employment of Persons With Disabilities in South Africa, 1998-2006. South African Journal of Economics, 76(3), 480-492.

Mitra, S., Posarac, A., \& Vick, B. C. (2011). Disability and Poverty in Developing Countries: A Snapshot From the World Health Survey. World Bank.

Mitra, S., \& Sambamoorthi, U. (2008). Disability and the Rural Labor Market in India: Evidence for Males in Tamil Nadu. World Development, 36(5), 934-952.

Mobarak, R., Khan, N. Z., Munir, S., Zaman, S. S., \& McConachie, H. (2000). Predictors of Stress in Mothers of Children With Cerebral Palsy in Bangladesh. Journal of Pediatric Psychology, 25(6), 427-433.

Mont, D., \& Cuong, N. V. (2011). Disability and Poverty in Vietnam. The World Bank Economic Review, 25(2), 323-359.

Murphy, N. A., Christian, B., Caplin, D. A., \& Young, P. C. (2007). The Health of Caregivers for Children With Disabilities: Caregiver Perspectives. Child: care, health and development, 33(2), 180-187.

Palmer, M. G., Thuy, N. T. M., Quyen, Q. T. N., Duy, D. S., Huynh, H. V., \& Berry, H. L. (2012). Disability Measures as an Indicator of Poverty: A Case Study From Viet Nam. Journal of International Development, 24(S1), S53-S68.

Patient Voices. (n.d.). https://www.patientvoices.org.uk/

Patient Voices. (2014). Saving Brains. Accessed January 11, 2017. https://www.patientvoices.org.uk/ savingbrains.htm 
Sawyer, M. G., Bittman, M., La Greca, A. M., Crettenden, A. D., Borojevic, N., Raghavendra, P., et al. (2011). Time Demands of Caring for Children With Cerebral Palsy: What Are the Implications for Maternal Mental Health? Developmental Medicine \& Child Neurology, 53(4), 338-343.

The African Child Policy Forum (ACPF). (2014). Access Denied: Voices of Persons With Disabilities From Africa. ACPF.

Trani, J.-F., \& Loeb, M. (2012). Poverty and Disability: A Vicious Circle? Evidence From Afghanistan and Zambia. Journal of International Development, 24(S1), S19-S52.

Trani, J.-F., \& VanLeit, B. (2010). Increasing Inclusion of Persons With Disabilities: Reflections From Disability Research Using the ICF in Afghanistan and Cambodia. Leonard Cheshire International.

Yeo, R., \& Moore, K. (2003). Including Disabled People in Poverty Reduction Work: "Nothing About Us, Without Us." World Development, 31(3), 571-590.

Publisher's Note Springer Nature remains neutral with regard to jurisdictional claims in published maps and institutional affiliations.

\section{Authors and Affiliations}

Joëlle Castellani ${ }^{1}$ - Omari Kimbute ${ }^{2}$. Charles Makasi ${ }^{2} \cdot$ Zakayo E. Mrango $^{2}$. Aggie T. G. Paulus ${ }^{1}$ - Silvia M. A. A. Evers ${ }^{1} \cdot$ Pip Hardy $^{3} \cdot$ Tony Sumner $^{3}$. Augusta Keiya $^{4} \cdot$ Borislava Mihaylova ${ }^{5,6} \cdot$ Mohammad Abul Faiz $^{7} \cdot$ Melba Gomes $^{8}$

1 Department of Health Services Research, Care and Public Health Research Institute (CAPHRI), Maastricht University, Maastricht, The Netherlands

2 Kilosa Station, National Institute for Medical Research, Kilosa, Tanzania

3 Patient Voices Programme, Pilgrim Projects Limited, Landbeach, UK

4 Dorcas Relief and Development, Handeni, Tanzania

5 Health Economics Research Centre, Nuffield Department of Population Health, University of Oxford, Oxford, UK

6 Institute of Population Health Sciences, Barts and the London School of Medicine and Dentistry, Queen Mary University of London, London, UK

7 Mahidol Oxford Tropical Medicine Research Unit (MORU), Mahidol University, Bangkok, Thailand

8 UNICEF/UNDP/World Bank/WHO Special Programme for Research \& Training in Tropical Diseases (TDR), World Health Organization, Geneva, Switzerland 